\title{
PATRISTISCHE HYMNEN - MITTELALTERLICHE HYMNEN* DEKONTEXTUALISIERUNG UND REKONTEXTUALISIERUNG IN DER LATEINISCHEN LITURGIE
}

Summary: The Latin Church has sung many shortened versions, or excerpts from the long poems of Prudentius's hymn-cycles (Cathemerinon and Peristephanon) since the Middle Ages. One of the most influential of these is the hymn Salvete flores martyrum, for Innocent's Day. The paper examines the structural and aesthetic principles which lead the - for us - unknown medieval interpretive community in creating this unique centonised latin hymn.

Key words: Prudentius: Cathemerinon 12, centonised medieval liturgic hymns, hymn Salvete flores martyrum, decontextualisation, recontextualisation, interpretive communities

Aus den zwei lyrischen Zyklen des größten Dichters des christlichen Altertums, ${ }^{1} \mathrm{~d} . \mathrm{h}$. aus dem zwölf Gedichte enthaltenden Cathemerinon und aus dem ursprünglich gleichfalls aus zwölf Gedichten bestehenden Peristephanon ${ }^{2}$ des Prudentius, wurden an

* Eine frühere Version des Aufsatzes: Patrisztikus himnuszok - középkori himnuszok. A dekontextualizálás és a rekontextualizálás útjai a latin liturgiában [Patristische Hymnen - mittelalterliche Hymnen. Wege der Dekontextualisierung und Rekontextualisierung in der lateinischen Liturgie]. Ókor IX (2010) Nr. 3, 56-63.

${ }^{1}$ So benennt J. BERGMAN den Dichter in seiner bedeutenden Monographie, die als Grundwerk der modernen Prudentius-Philologie gilt (Aurelius Prudentius Clemens, der größte christliche Dichter des Altertums. Zur Erforschung der spätlateinischen Literatur 1. Eine Einführung in den heutigen Stand der Prudentius-Forschung und eine Studie über die Hymnensammlung „Die Stunden des Tages “(Cathemerinon liber). Dorpat 1921).

${ }^{2}$ Zum Teil anhand früherer Literatur vertritt Christian Gnilka die These, dass das Gedicht VIII aus drei unabhängigen Epigrammen zusammengefügt wurde; er ist des Weiteren davon überzeugt, dass auch der große Romanus-Hymnus ein unabhängiges Werk sein könnte. (Zum Epilogus des Prudentius, in GNILKA, CHR.: Philologische Streifzüge durch die römische Dichtung. Basel 2007, 459-493, hier 462.) Der zusammengeflochtene Epigrammzyklus und der letztere Hymnus sind zwar Werke von Prudentius, können jedoch ursprünglich nicht zum Zyklus gehört haben und wurden erst bei einer späteren Redaktion eingefügt, dementsprechend besteht das Buch Peristephanon nicht aus vierzehn Gedichten. Gnilkas überzeugende These konnte noch nicht in den großen literaturgeschichtlichen Zusammenfassungen rezipiert werden und ich habe den Zyklus auch nicht so in meiner Dissertation wahrgenommen: DÉRI, B.: A részek 
verschiedenen Orten und zu verschiedenen Zeiten auf unterschiedliche Weisen viele Gedichte bzw. deren Teile in der Liturgie des abendländischen christlichen Mittelalters gesungen - zum größten Teil also nicht das Original im vollen Umfang, sondern in gekürzter Form. Mehrere seiner Gedichte bzw. die aus diesen geformten Hymnen werden sogar bis heute im Offizium (Stundengebet) ${ }^{3}$ oder bei der Lichtfeier der römisch-katholischen Kirche am Karsamstag ${ }^{4}$ gesungen oder gesprochen. ${ }^{5}$

Grundlegende Ausgaben der lateinischen liturgischen Dichtung - hier müssen an erster Stelle die Analecta hymnica von Dreves-Blume ${ }^{6}$ und deren populäre Zusammenfassung, Ein Jahrtausend liturgischer Hymnendichtung, ${ }^{7}$ erwähnt werden - oder das Handbuch von Josef Szövérffy, ${ }^{8}$ dem bedeutenden ungarischen Forscher auf dem Gebiet der mittelalterlichen Hymnen, beschreiben genau, aus welchen Strophen oder Zeilen des Prudentius-Corpus die „prudentianischen“ liturgischen Hymnen zusammengesetzt sind. Aus diesen Arbeiten geht auch hervor, welche die ersten liturgischen Manuskripte sind, in denen diese gekürzten und neu gestalteten Prudentius-Hymnen zum ersten Mal auftauchen.

Aus den längeren Gedichten des Prudentius wie auch des Sedulius ${ }^{9}$ aus dem 5. Jahrhundert sind also nur Teile in die konstitutiven Elemente der Liturgie aufgenommen worden. Aus der weiteren Dichtung des christlichen Altertums sind die achtstrophigen Gedichte des Ambrosius von Mailand ${ }^{10}$ bzw. die gleichfalls kurzen frühmittelalterlichen so genannten ambrosianischen ${ }^{11}$ und die gallikanischen Hymnen ${ }^{12}$ aus dem 6. Jahrhundert nach unserem heutigen Wissen ohne Verkürzung ${ }^{13}$ in dem Offizium der abendländischen Kirche zu finden. Dabei spreche ich weder von den anonymen lyrischen Werken (Te Deum, Exsultet, Gloria), ${ }^{14}$ die nicht den Normen der

és az egész. Prudentius Cathemerinon címü himnuszciklusának szerkezete [Die Teile und das Ganze. Die Struktur des Zyklus Cathemerinon des Prudentius]. Budapest 2001, 13-14, 165. - Die Zahl zwölf kann auf jeden Fall auch hier als ein schönes numerologisches Symbol fungieren.

${ }^{3}$ Siehe unten im Kapitel: Centonisierte liturgische Hymnen aus Prudentius' Hymnen, 229-231.

${ }^{4}$ Den Prozessionshymnus Inventor rutili singt man in der wiederbelebten Graner Liturgie (ritus Strigoniensis) in Ungarn bei der Lichtfeier.

${ }^{5}$ Zu einem Überblick s. WILle, G.: Musica Romana: Die Bedeutung der Musik im Leben der Römer. Amsterdam 1967, 291-298. Zum Cathemerinon 12: 296-297.

${ }^{6}$ Dreves, G. M.: Lateinische Hymnendichter des Mittelalters [Analecta Hymnica Medii Aevi L]. Leipzig 1907, 22-46 (mit Einleitung).

${ }^{7}$ DREVES, G. M. - BLuME, CL.: Ein Jahrtausend lateinischer Hymnendichtung. Eine Blütenlese aus den Analecta Hymnica mit literarhistorischen Erläuterungen. I. Teil: Hymnen bekannter Verfasser. Leipzig 1909, 15-24 (mit Einleitung).

${ }^{8}$ SzÖVÉRFFY, J.: Die Annalen der lateinischen Hymnendichtung. Ein Handbuch. I. Die lateinischen Hymnen bis zum Ende des 11. Jahrhunderts. Berlin 1965, 82-92. Über die Gedichte des Prudentius im Allgemeinen: 78-82, 92-94.

${ }^{9}$ Siehe unten im Kapitel „Prudentius und die „langen“ Hymnen“, 229-231.

${ }^{10}$ SZÖVÉRFFY (Anm. 8) 48-68.

${ }^{11}$ SZÖVÉRFFY (Anm. 8) 95-96 (bei ihm: ambrosianisch-mailändische Dichtung); Paulinus, Sedulius, italienische und irische Hymnen: 96-109; Gregor der Große: 140-144.

${ }^{12}$ SZÖVÉRFFY (Anm. 8) 110-119; Venantius Fortunatus: 128-138. nicht hierzu.

${ }^{13}$ Die Auslassung der ersten Strophe von Intende qui regis Israel/Veni Redemptor gentium gehört

${ }^{14}$ SZÖVÉRFFY (Anm. 8) 15. Bis heute unersetzbar: KÄHLER, E.: Studien zum Te Deum und zur Geschichte des 24. Psalms in der Alten Kirche. Göttingen 1958. 
klassischen metrischen Dichtung, sondern der Tradition der biblischen hebräischen Dichtung folgen, noch von den Werken, die in die Liturgie nicht aufgenommen worden sind, wie z. B. die Hymnen des Hilarius. ${ }^{15}$

Diese Feststellungen sind eigentlich literatur- und liturgiegeschichtliche Gemeinplätze, ich glaube allerdings, dass vier wichtige Fragestellungen in diesem $\mathrm{Zu}$ sammenhang im Prinzip nicht überprüft worden sind. Diese vier Fragen entsprechen den vier Kapiteln dieses Aufsatzes.

Erstens, ob der Grund dieser Verkürzung eine individuelle Erscheinung ist oder ob sie sich in eine größere literatur- und geistesgeschichtliche Strömung einfügt. (I. Dekontextualisierung und Rekontextualisierung christlicher literarischer Texte der Spätantike)

Zweitens, nach welchen literarischen Techniken die langen Hymnen generell und speziell die von Prudentius zu mittelalterlichen liturgischen Hymnen umgestaltet worden sind. (II. Die ars centonizandi)

Drittens, auf welcher Grundlage, nach welchen Prinzipien die ursprünglichen patristischen Hymnen ausgewählt und umgestaltet worden sind. $\mathrm{Zu}$ diesem tritt noch die ästhetische Beurteilung des Zustandegekommenen: Sie wurden von der großen Zahl der für die Liturgie verantwortlichen Geistlichen als für den Gottesdienst sehr geeignete Texte befunden. (III. Die ambrosianische Ästhetik)

Viertens kommt auch die mediale und historische Frage hinzu: Welche Interpretationsgemeinschaft ${ }^{16}$ hat wann und wo die genannte Umgestaltung realisiert. (IV. Die Art und Weise und die Zeit der Interpretationsgemeinschaft)

\section{DEKONTEXTUALISIERUNG UND REKONTEXTUALISIERUNG CHRISTLICHER LITERARISCHER TEXTE DER SPÄTANTIKE}

Mit der ersten Frage kann ich mich nicht einmal skizzenhaft befassen: Von ernsthafter, moderner, synthetischer Zusammenfassung habe ich keine Kenntnis. So viel dazu: ${ }^{17}$ Die umfangreichen christlichen literarischen Texte der Spätantike haben, aus ihrem ursprünglichen, in der Gemeinschaft schwer zu rezipierenden Kontext herausgenommen und diesem gegenüber verschoben (d. h. im Prozess einer gewissen Dekontextualisierung), in der frühmittelalterlichen und karolingisch-postkarolingischen Zeit einen neuen Kontext gewonnen. (Das kann man eine Phase der Rekontextualisierung nennen.) Schließlich wurden sie durch kirchenrechtliche Regelung als allgemeine und stabile Objekte der Bildung für lange Jahrhunderte, fast bis zur Gegenwart gefestigt und durch die medialen Techniken der Übergabe für die große Menge zugänglich. (Unter Übergabe verstehe ich sowohl die Vervielfältigung als auch den Prozess des Aneignens, Unterrichtens und Lernens.) Obwohl in Bezug auf das zweite

\footnotetext{
${ }^{15}$ SZÖVÉRFFY (Anm. 8) 69-73.

${ }^{16}$ Ich benutze hier den von S. FiSH eingeführten Terminus interpretive community. (Is there a text in this class?: The authority of interpretive communities. Cambridge, MA 1980.)

${ }^{17} \mathrm{Im}$ Folgenden halte ich es nicht für sinnvoll, die allgemeinen liturgischen Kenntnisse mit Hinweisen auf die Fachliteratur zu unterstützen.
} 
Vatikanische Konzil eine sehr schwerwiegende Zerstörung der liturgischen Form vollzogen wurde, ${ }^{18}$ muss so viel anerkannt werden, dass die oben beschriebene Ordnung der Liturgie und deren Bildungsinhalt im Prinzip spurenhaft auch heute noch gültig sind.

Dieser zweifache Prozess des Auslesens und des Neustrukturierens macht einen gravierenden Unterschied zwischen dem Fortleben der nicht christlichen und der christlichen Antike - sei es hinsichtlich der äußerlichen (physischen), sei es der innerlichen (geistigen) Formen des Tradierens. ${ }^{19}$

Was die nicht christlichen Texte betrifft, ihre Seinsweise ist die einsame, zeitlich nicht bestimmte, freie (auf freier Textauswahl basierende, quantitativ nicht definierte) Lektüre von in keine Hierarchie geordneten, im Allgemeinen vollständigen Werken - im Gegenteil dazu spielten die Lektüre von Exzerpten und Florilegien, des Weiteren (was den Anlass und die Modi der Ausführung betrifft) der Gesang in der Gemeinschaft (wie der humanistische Odengesang) eine zweitrangige Rolle.

Demgegenüber stand im Mittelpunkt des Textkanons der christlichen Antike und des auf diese folgenden Mittelalters die Heilige Schrift, die nicht nur als zusammenhängendes Ganzes gelesen wurde (also nicht nur als ein ganzes Buch oder, hinsichtlich der Form und der Narration, in geschlossenen Einheiten wie einem Psalm oder einer prosaischen Perikope), sondern sogar noch in Sätze aufgeteilt. Des Weiteren waren all die übrigen religiösen Texte prosaische oder poetische Kommentare dieses kanonischen Textes, bildeten also ein in allen Hinsichten zusammenhängendes und quantitativ definiertes System. Die Aufführung des Textmaterials selbst war ein religiöser Akt, ein officium der Lippen, das durch strenge Regeln bestimmt war, sowohl was den Modus der Aufführung (vom Rezitativ bis zum melodischen Gesang, vom Solo bis zum Tutti, also dem Gesang der ganzen Gemeinde), als auch was den Ort und die Zeit der Aufführung, sogar die dazugehörenden Bewegungen betrifft. Die typische Form der Aufführung dieser Texte war eine gemeinschaftliche. Die quantitativ nicht definierte, einsame Lektüre der Bibel oder beispielsweise eines Bibelkommentars, ein einsam vorgesungener Hymnus waren sekundäre Erscheinungen, die aus bestimmten Lebenssituationen oder aus der Zugehörigkeit zu einer bestimmten Elite resultierten.

Die Bibel und die patristische und mittelalterliche religiöse Literatur leben also ein doppeltes Leben, sowohl was die Textüberlieferung als auch was die Lesung und die Aufführung betrifft. Die ganzen Werke (wie die Bibel, eine Reihe von Reden, ein langer Hymnus von Prudentius oder sogar eine ganze Legende eines Heiligen) werden während der einsamen Lektüre, während der Beschäftigung mit dem Werk (wie des Unterrichts, des Kommentierens) als autonome Werke gelesen ${ }^{20}$ von einer engen

\footnotetext{
${ }^{18}$ Ich darf hier ausnahmsweise ohne weitere Literaturangaben an die entsprechende theologische und kirchenpolitische Tätigkeit des Papstes Benedikt XVI. erinnern. Im deutschen Sprachraum ist M. MOSEBACHs mit besonderer Schärfe und sprachlicher Schönheit formulierte Kritik bekannt: Häresie der Formlosigkeit. Die römische Liturgie und ihre Feinde. München 2007.

${ }^{19}$ Assmann, A. - Assmann, J.: „Kanon und Zensur“. In Assmann, A. - Assmann, J. (Hrsg.): Kanon und Zensur [Archäologie der literarischen Kommunikation 2]. München 1987, 7-27.

${ }^{20}$ Jedoch bleiben sie immer im Kontext des durch die liturgische Kultur lebenden Textmaterials.
} 
„intellektuellen“ Gruppe ${ }^{21}$ während die Kleriker-, Mönch- und Schülergemeinde und auch die theologische Elite als Teil dieser größeren Gemeinschaft von mittelalterlichen Klerikern ein nicht allzu großes - vom 10. Jahrhundert an aus heutiger Sicht gesehen etwa dreibändiges - Textkorpus der Messe und des Offiziums Jahr für Jahr, einige Teile sogar täglich, und das Ganze laut, auf verschiedenen Stufen des Gesanges (ProsaRezitation - melodischer Gesang) wiederholte.

Wer mit dem Usus der kirchlichen Kultur nicht vertraut ist, wird vielleicht aus einigen Beispielen ersehen, worum es hier geht. Stellen wir uns vor, es wäre, wenn man sich im Winter in eine Heidelberger ${ }^{22}$ Kneipe setzt, als obligatorisch vorgeschrieben, zuerst das Thaliarchus-carmen des Horaz (,,Vides, ut alta ... ") zu singen, dann ein Kapitel einer Agrarschrift zu rezitieren oder aus dem zweiten Buch der Georgica über den Weinbau, dazu den Servius-Kommentar, dann das „Persicos odi ... " zu singen, dazu eine Passage aus Nisbet-Hubbard, dann einen karolingischen moralisierenden Text über die Nüchternheit vorzulesen, dann mit einem Trinklied aus den Carmina Burana zu schließen. Dazwischen wäre es ebenso vorgeschrieben, was der Kellner sagt, in welcher Reihenfolge, von welchem Wein und wie viel man trinken darf. Und all dies betrachtet man nicht als Horaz-, Vergilius- und Carmina Burana-, Servius- und Nisbet-Hubbard-Texte, sondern als eine einzige Einheit. Eine Art officium gulae.

Die liturgische Lesung des von Hieronymus übersetzten oder in einer nicht ganz genau definierbaren Weise revidierten Bibeltextes wurde durch ein Perikopensystem bzw. durch die in den Matutinen (dem Nachtoffizium) fixierte Ordnung der lectio continua organisiert. Die Grundzüge dieser haben sich in der patristischen Epoche entfaltet und das für die karolingische Zeit im Wesentlichen fixierte System galt in ganz Europa. Die Bibel, vor allem die Psalmen, machten auch den großen Teil der gesungenen Sätze aus. In ihrem kultischen Status steht die Euchologie, das Korpus der ursprünglich für den Kult bestimmten nichtbiblischen Gebetstexte, der Heiligen Schrift nahe. Die christliche Gebetsdichtung wurde in den Sacramentaria ausgelesen und fixiert.

In die letzten zwei Gruppen gehören die mit einer kultischen Rolle später ausgestatteten und dementsprechend nicht nur einmal aufgeführten, sondern immer wieder repetierten Texte. Die in prosaischer Form geschriebenen sind in erster Linie Gegenstände der Homiletik, also die ursprünglich rhetorischen Texte. Die spätantike und die auf diese folgende christliche Rede wurde in den Abschnitten der Homilien und Sermones der Matutin vorgelesen, aber zum Teil (oft schon während ihrer Ausformung) spielten die Literatur über die Leiden der Heiligen und die religiöse Unterhaltungsliteratur eine ähnliche Rolle - diese beiden, als die Gattung der mittelalterli-

\footnotetext{
${ }^{21}$ Die Legende und andere Erbauungsliteratur, besonders in den Volkssprachen, konnte auch breitere Leserschaften erreichen.

${ }^{22}$ Mit diesem halbwegs ernsthaften Exempel möchte ich mich bei Herrn Prof. Jürgen Paul Schwindt und dem Heidelberger Philologischen Seminar für die Einladung bedanken, in deren Rahmen eine frühere Version dieses Aufsatzes vorgetragen wurde (11. Januar 2011, Ruprecht-Karls-Universität Heidelberg, Seminar für Klassische Philologie).
} 
chen Legende, bekamen ihren liturgischen Ort im Rahmen des Matutinums. Schließlich, dem Stoff der Homiletik und der Legenden ähnlich, wurde nicht einmal die religiöse Dichtung der lateinischen Patristik mit dem Ziel verfasst, Teil der Liturgie zu werden, sei es als eine Gemeinde-Lyrik, wie nach dem Zeugnis der Zeitgenossen, etwa des Augustins (Confessiones 9. 7. 15), die Hymnen des Ambrosius, sei es als für das private Gebet gedacht (auch Augustin, ebd. 9. 12. 32), wie man es von Prudentius ahnen kann.

Die wertvollen, aber in einiger Hinsicht fraglichen Stücke der spätantiken religiösen Dichtung (vor allem die Hymnen des Prudentius) haben sich dann durch geeignete Verkürzungen und Umgestaltungen neben die die Gattungsnormen bestimmenden Psalmen und die Gedichte des Ambrosius gestellt (soweit man wissen kann, hat zuerst Sankt Benedikt die Gedichte des Ambrosius in die Liturgie des Stundengebets eingeordnet), und im Mittelalter entstanden metrische Texte in großer Zahl, die verschiedenen nicht- oder paraliturgisch-halbliturgischen Untergattungen angehören. „Das Repertoire der liturgischen Texte ist ein unikales Beispiel dafür, dass eine Sammlung literarischer Herkunft eine seltsame räumlich-zeitliche Verbreitung erfährt und so in einer von den Umständen ihrer Genese unabhängigen Performanz und für eine solche Öffentlichkeit bestimmend wird. Man kann hinzufügen: bestimmender, als sie unter den Umständen ihrer Genese hätte werden können. ${ }^{\text {‘23 }}$ Daher wurde Prudentius während der europäischen Geschichte der am meisten vorgetragene, gesungene Dichter der Antike, zwar, dem Geist der Liturgie entsprechend, im Wesentlichen ohne Namen - aber diese Anonymität ist in Bezug auf die Entstehung der liturgischen Prudentius-Hymnen treffend. Jedoch möchte ich die Konklusion nicht vorzeitig ziehen!

\section{DIE ARS CENTONIZANDI}

Was den zweiten Problemkreis betrifft, muss man zuerst die Frage stellen, ob die Verkürzung langer metrischer Texte (Hymnen) kirchlichen Vorschriften oder anderen Gründen entsprach. Ohne indirekte, eindeutige zeitgenössische Zeugnisse kann man nur feststellen, dass im Vergleich zu der griechischen oder anderweitigen östlichen (syrischen, koptischen) oder sogar iberischen lateinischen (mozarabischen) Liturgie (wo die Liturgie später von manchmal sehr umfangreichen metrischen Texten überfüllt wurde) die ,zentrale“ lateinische, römische Auffassung auch im Allgemeinen der nichtbiblischen Dichtung gegenüber sehr enthaltsam war. Selbst die Liturgie der Stadt Rom hat viele Jahrhunderte lang nicht einmal die Reform des Benedikt akzeptiert. Das Textmaterial ihrer Gesänge entnahm sie in erster Linie den Psalmen; ihre Paraphrasierung hatte sie nicht zum Ziel. Als einzige sehr produktive (und man kann vielleicht sagen: sehr moderne) literarische Technik behauptete sich der Cento, die

\footnotetext{
${ }^{23}$ Wie der Mitarbeiter unseres Budapester Seminars M. I. FÖLDVÁRY sehr prägnant formulierte: Patrisztikus beszédek és kommentárok a latin liturgia kontextusában [Patristische Homilien und Kommentare im Kontext der lateinischen Liturgie]. Ókor IX (2010) Nr. 3, 60-70, hier 64.
}

Acta Ant. Hung. 56, 2016 
Collage. Die Mehrzahl der Gesänge der lateinischen Liturgie bilden einige herausgehobene biblische Zitate, in erster Linie aus den Psalmen, die so einen besonderen Akzent bekamen: Sie konnten während des Festes und anderer Aspekte neu bewertet werden und wurden auch literarisch neu gestaltet. Es ist wirksam, und im technischen Sinne ausgesprochen geschickt, wenn mehrere Psalmen so verknüpft werden, dass sie in eine eigentümliche, gegenseitige interpretatorische Beziehung zueinander treten. Auch im quantitativen Sinne zielte die Hauptströmung des lateinischen Christentums im Vergleich zu den byzantinischen und orientalischen Kirchen auf Ökonomie, und vielleicht wollte die Dichtung des Ambrosius schon an sich diesem Ziel entsprechen, immerhin trug sie zur Fixierung dieser Normen bei.

Wie bekannt, sind die authentischen Hymnen des Ambrosius achtstrophig, und die Strophen bestehen aus je vier jambischen Dimetra. Wie ich bereits früher aufgeworfen habe: ${ }^{24}$ Die Tatsache, dass die Gedichte achtstrophig sind, hängt vielleicht damit zusammen, dass der Psalm 118/119 aus 22 Teilen mit jeweils acht Verspaaren besteht, die immer mit einem der 22 Buchstaben des hebräischen Alphabets des AbecedariusPsalms 118 anfangen. Auch spielte der Psalm 118 mit Gewissheit schon im lateinischen Stundengebet des 4. Jahrhunderts eine herausgehobene Rolle. (Als Nachfolge dieses Offiziums können sowohl das mailändische, so genannte Ambrosianische als auch das römische Offizium genannt werden - letztere Variante ist das Offizium der Benediktiner.) Dieser Psalm wurde im Vergleich zu den anderen Psalmen des Psalters eigenartig behandelt, indem er aufgeteilt (mit kirchlichem Terminus: dividiert) vorgetragen wurde, und dieser Text, der den Christen an seine Pflichten erinnert, wurde jede Woche in gleicher Ordnung, tagsüber, in den so genannten kleinen Horen vorgetragen. ${ }^{25}$ Ambrosius verfasste sogar einen umfangreichen Kommentar zu diesem Psalm, etwa zu der Zeit ${ }^{26}$ in der er auch die Hymnen schrieb (386). Obwohl man, soweit ich sehe, keinen direkten Beweis für diese Begründung der achtstrophigen Form hat, scheint mir das Muster des erwähnten Psalmes als eine solche nahe liegend zu sein.

\section{PRUDENTIUS UND DIE „LANGEN“ HYMNEN}

Wie erwähnt, wurden die lyrischen/episch-lyrischen Gedichte des Prudentius, die auch nach antiken Maßstäben als umfangreich gelten, vor allem das zwölf tägliche oder festliche Gedichte enthaltende Cathemerinon ${ }^{27}$ und das ursprünglich vielleicht

\footnotetext{
${ }^{24}$ DÉRI (Anm. 2) 189.

${ }^{25}$ Noch dazu waren im ambrosianischen Offizium die Psalmen des Matutinums am Samstag die Passagen 1-11 bzw. 12-22 des 118. Psalms, in zweiwöchigem Wechsel.

${ }^{26}$ Etwas später (387/388) trug er die 22 Homilien vor, die als Grundlage des Kommentars dienten; das große Werk beschäftigte ihn aber schon früher.

${ }^{27}$ Ihre Länge beträgt zwischen 100 und 220 Zeilen.
} 
auch zwölf Gedichte enthaltende Peristephanon ${ }^{28}$ - der Zyklus für die Heiligen -, in die mittelalterliche lateinische Liturgie nur in einer mehr oder weniger umgestalteten, also durch verschiedene Techniken gekürzten Form aufgenommen. Dasselbe passierte dem 23-strophigen (also kürzeren als die des Prudentius) Hymnus $A$ solis ortus des Sedulius, einem Abecedarius aus dem 5. Jahrhundert. Eine seltenere Methode ist die des mozarabischen Ritus, ${ }^{29}$ der einige Hymnen des Prudentius in den einzelnen horae durchgängig aufgeteilt verwendet.

Das mozarabische Offizium ${ }^{30}$ setzt beispielsweise die fünfzehn Teile des 220zeiligen, 44-strophigen siebenten Hymnus ( $O$ Nazarene lux Bethlem Verbum Patris) zur Fastenzeit von Montag bis Samstag für die tertia und sexta, zwischen Montag und Donnerstag für die nona, aber nicht fortlaufend an den einzelnen Tagen an, sondern - in einer quasi abstrakten Ordnung, der man nur im Buch folgen kann - so, dass in der tertia die Strophen 1-16, in der sexta die Strophen 17-35, in der nona 36-44 (und die Doxologie) vorgetragen werden; und so folgen zum Beispiel montags nach den Strophen 1-4 die Strophen 17-20 und 36-38. Diese erste Paraphrase des Buches Jona in der Weltliteratur, der „Einschub“ eines Drittels dieses Hymnus (fünfzehn Strophen, 75 jambische Trimetra), wurde also in der mozarabischen Liturgie nicht fortlaufend, sondern von Dienstag bis Samstag in den sextae horae vorgetragen, durchaus ohne Rücksicht auf die Linearität der Narration!

In dem so genannten fränkisch-römischen Ritus ${ }^{31}$ wurde das Gedicht $A$ solis ortus cardine ebenfalls an der Strophengrenze aufgeteilt. Die ersten sieben Strophen wurden im Mittelalter zum Weihnachtshymnus mit dem Incipit $A$ solis ortus cardine; so ergeben sie mit einer addierten Doxologie eben den ordentlichen Umfang eines ambrosianischen Hymnus. Dann wurden auch aus dem zweiten Teil ganze Strophen herausgenommen $(8-9,11$ und 13), und dieser kürzere Hymnus wurde als Haupthymnus vom Dreikönigstag mit dem Incipit Hostis Herodes impie gesungen. ${ }^{32}$

Im vorigen Fall kann man im Wesentlichen den spätantik-mittelalterlichen, aber auch heute präsenten Usus beobachten, dem gemäß die längeren Psalmen (und dann, seit dem Mittelalter bis heute, die Hymnen) geteilt (dividiert) werden. In der mozarabischen Verwendung sind also - es sei bemerkt, nicht alle sind so kompliziert den horae desselben Feiertages (oder einer Woche) einzelne Teile zugeordnet, aber so, dass der Eindruck der Einheit des Werkes präsent bleibt, selbst wenn es nicht bemerkt wird. An entsprechenden (oder sogar an nicht so sehr entsprechenden) Punkten

\footnotetext{
rechnen.

${ }^{28}$ Zwischen 90-584 Zeilen, wenn wir VIII (18 Zeilen) und X (1140 oder 1135 Zeilen) nicht dazu-

${ }^{29}$ Breviarium Gothicum. Ed. Francisco Antonio de LoREnZANA. Migne Patrologia Latina 86, cc. $269 \mathrm{ff}$.

${ }^{30}$ Ebd.

${ }^{31}$ Mit diesem Begriff bezeichne ich die Variante des römischen Ritus, die sich im fränkischen Reich entwickelte und die danach in vielen Versionen in verschiedenen Gebieten Europas weiterlebte, die früheren großen Riten (mozarabisch, ambrosianisch, gallikanisch, beneventanisch) praktisch verdrängend. Die wichtigsten Züge des Gebrauches der Hymnen stellt Szövérffy vor: SzÖVÉRFFY (Anm. 8) 82-84.

${ }^{32} \mathrm{Zu}$ Sedulius s. SZÖVÉRFFY (Anm. 8) 98 ff. Im mozarabischen Ritus wird am Dreikönigsfest die Passage Hostis Herodes impie eigentlich am Stück zu Ende gesungen. LoREnZANA, Migne Patrologia Latina 86 (Anm. 29) cc. 184-185.
}

Acta Ant. Hung. 56, 2016 
wird der Textfluss aufgehoben, damit er nach Einschub von anderen Texten fortgesetzt wird, in einer anderen hora. Im anderen Fall aber werden die herausgehobenen Teile anderen Festtagen zugewiesen (im Falle von Hostis Herodes im fränkisch-römischen Ritus sogar nicht einmal fortlaufend, sondern so, dass die Strophen, deren Thematik nicht mit dem Dreikönigstag zusammenhängt, übersprungen werden), und so entstehen zwei selbstständige Hymnen. Sedulius' Gedicht macht es schon an sich dadurch möglich, dass es im Wesentlichen eine fortlaufende Narration über das Leben Jesu ist und die nicht in gleichem Maße ausgearbeiteten thematischen Teile (mehrere Strophen) im gegebenen Fall ohne weitere Geschicklichkeit einem Fest zuzuweisen sind.

Damit diese Methode dauerhaft und fruchtbar werden konnte und nicht als eine die Inspiration ersetzende Zwangslösung oder als ein literarisches Spiel „funktionierte", das heißt, damit die entstehende neue Einheit tatsächlich als ein liturgisches Gedicht fortleben konnte, war wohl ein bestimmter literarischer Geschmack nötig. Viel mehr war aber nötig im Falle einer Gruppe der Prudentius-Hymnen, von denen ich einen im Folgenden ausführlich analysiere.

\section{CENTONISIERTE LITURGISCHE HYMNEN AUS PRUDENTIUS' HYMNEN}

Damit wir uns nicht in Einzelheiten verlieren, typisiere ich nur die sechs centonisierten Hymnen, die in der fränkisch-römischen Tradition allgemein verbreitet waren, aber man darf nicht vergessen, dass weitere Hymnen sporadisch vorkommen.

Der Hymnus der hora vom Dienstagmorgen (Laudes), Ales diei nuntius, wird aus 16 Zeilen (1-8, 81-84 und 97-100) des Gedichts mit demselben Incipit zusammengestellt. Ein weihnachtlicher Offizienhymnus ist auch das Corde natus ex Parentis, das aus den Versen 10-12, 19-27 und 109-111 des neunten Gedichts besteht. Der Prozessionshymnus der Feuerweihe vom Karsamstag ist das Inventor rutili, dieses besteht aus den Zeilen 1-32 und 149-164 des fünften Gedichts (aber es bestehen gravierende Unterschiede in den spätmittelalterlichen Quellen, was die Nummer der Verse und Strophen betrifft). Diese drei Hymnen wurden also aus den vier- und dreizeiligen, vollen Strophen der ursprünglichen Gedichte aufgebaut, die, obzwar mit Auslassungen, fortlaufend ausgelesen und neu zusammengefügt wurden.

Viel interessanter ist der Aufbau des Hymnus der Laudes am Mittwoch, Nox et tenebrae, der aus 16 Versen $(1-8,48-49,52,57,59-60$ und 67-68) des zweiten Gedichtes des Cathemerinon vom selben Incipit besteht - während andere 16 Zeilen desselben Gedichts (25, 93-94 und 96-108) den Hymnus der Laudes am Donnerstag Lux ecce surgit aurea ausmachen. Wie man sieht, sind die beiden Hymnen so verfertigt (nicht ohne Geschick!), dass nicht nur zusammenhängende vierzeilige Strophen, sondern auch einzelne oder Paarverse dem Original entnommen wurden, aber ein Empfinden für den Textfluss ist auch hier präsent. (Nicht die festlichen Hymnen, also der von Weihnachten, der von Karsamstag usw. zeigen die elementare Bedeutung des Prudentius an, sondern dass seine Texte von Dienstag bis Donnerstag - abgesehen von den Festtagen - in der hora der laudes viele Jahrhunderte lang praktisch in ganz 
Europa gesungen wurden, und diese so [nebst den zwei Ambrosius-Hymnen, die in den vorigen Tagen der Woche anfielen, und neben den zwei Gregorius dem Großen zugeschriebenen Gedichten] das ausschließliche Hymnenrepertoire dieser eminenten hora bilden! Man kann durchaus feststellen, dass aus der Dichtung der Antike in der ganzen Geschichte am öftesten die Laudes-Hymnen des Ambrosius, des Gregorius und des Prudentius vorgetragen wurden, aber weil Prudentius für drei Texte verantwortlich zeichnet, steht er den beiden anderen in dieser Hinsicht voran...)

Komplexer als alle ist schließlich der Gegenstand meiner weiteren Analysen. Der Hymnus des Festes der Unschuldigen Kinder, das Salvete flores martyrum, wurde aus 32 Zeilen $(125-128,134,129-130$, 132, 93-94, 97, 99, 101-102, 107$112,117,114,113,115,134,137,138,136)$ des zwölften Gedichts des Cathemerinon zusammengesetzt, das in den Handschriften nicht dem Festtag der unschuldigen Kinder, sondern dem Dreikönigstag zugeschrieben wird. Die Selbstständigkeit des Hymnus wird wohl durch die von den unabhängigen Prudentius-Handschriften getrennte, stabile Textüberlieferung aufgezeigt: vor allem durch die Tatsache, wie stabil die Reihenfolge der Verse ist, aber auch, dass zum Beispiel das Satelles, i, ferrum rape des Verses 99 regelmäßig in der Variante Ferrum, satelles, arripe im liturgischen Hymnus fixiert wurde.

Diese varia lectio ist auch in zahlreichen unabhängigen Prudentius-Kodizes zu finden. Es ist freilich unmöglich, die vielen tausend tradierten liturgischen Handschriften zu vergleichen, um zu eruieren, wie häufig die ähnlichen „Kreuzungen“ sind. Allerdings abgesehen von kleineren Abweichungen, die aber auch in der unabhängigen Prudentius-Überlieferung zu finden sind, z. B. ist der Text des Esztergomer Offiziums aus dem dreizehnten Jahrhundert ${ }^{33}$ bis auf zwei kleine Abweichungen $^{34}$ völlig identisch mit der Dreves-Blume-Edition, ${ }^{35}$ die auf authentischen, frühen westlichen Quellen basiert!

Nicht eng gehören dem Thema die Verwendungen an, die aus dem zwölften Gedicht des Cathemerinon während Reformen der frühen Neuzeit ${ }^{36}$ oder in dem der Offizienreform des zweiten Vatikanischen Konzils entsprechenden, so genannten Lentini-Hymnarium zustande kamen ${ }^{37}$ - diese bespreche ich hier nicht.

${ }^{33}$ Breviarium notatum Strigoniense (s. XIII). Edited and introduced by J. SZENDREI [Musicalia Danubiana 17]. Budapest 1998 (heute im Kloster der Prämonstratenser, Strahov/Prag; Signatur: DE. I. 7), $29^{v}$.

${ }^{34}$ V. 2=126: Anstatt von limine, das auch in den liturgischen Manuskripten allgemein ist, steht im ungarischen liturgischen Kodex limite. V. 8=132: Anstatt von corona steht coronis, aber dies ist die Form, die in den maßgeblichen Prudentius-Ausgaben steht. Die letzte, doxologische Strophe des Graner Breviariums ist auch identisch mit dem von Dreves-Blume edierten.

${ }^{35}$ DREVES-BLume (Anm. 7) 18.

${ }^{36}$ Pius V. führte in seinem Breviarium Romanum (1568), im Zusammenhang mit der Erhöhung des Festes der Unschuldigen Kinder in die „duplex II classis“, den Hymnus Audit tyrannus anxius und als seine Division den Hymnus Salvete flores martyrum ein. Des Weiteren finden sich die Hymnen $O$ sola magnarum urbium (für das Dreikönigsfest) und Quicumque Christum quaeritis (für die Verklärung des Herrn) auch schon im Breviarium des Papstes Pius V.; es geht um Strophenauslesen mit kleineren Textänderungen, die man für der humanistischen Philologie zugehörig erklären kann.

${ }^{37}$ Magi videntes und Quicumque Christum quaeritis (für das Dreikönigsfest). 


\section{DER LITURGISCHE HYMNUS SALVETE FLORES MARTYRUM}

Die Abbildungen (SS. 234-235) stellen auch ohne Kommentar die Technik der Centonisierung dar: Hier strukturiert sich der Text tatsächlich aus Centos, aus Textstücken. Auch ganze Strophen werden fließend in die neue Struktur aufgenommen, aber auch einzelne Zeilen, und zwar nicht mit einfachen Auslassungen, also nicht in der Reihenfolge des Originals. Die Änderung des Umfangs bringt gravierende ästhetische Resultate mit sich, denn es geht hier nicht um irgendein mechanisches Ausschnittsverfahren, sondern um eine durchaus wohlerwogene Neustrukturierung auf höchstem Niveau.

Man muss ein wichtiges philologisches Problem betrachten. Um über die Struktur des Originals sprechen zu können - wir möchten sogar numerische Beobachtungen anstellen -, wäre es wichtig zu wissen, wie genau sein Textzustand ist. Christian Gnil$\mathrm{ka}^{38}$ ist der Meinung, die letzte Strophe (vier Zeilen) des Cathemerinon XII könne nicht von Prudentius stammen. Er meint, sie sei eine schwache Verdopplung der vorigen Abschlussstrophe, also eine „Doppelfassung“, die durch eine verfälschte vertretende Strophe entstand, ein ,parasitärer Auswuchs“ auf dem „künstlerischen Organismus“. Gnilka hat in zahlreichen hervorragenden Aufsätzen Interpolationen verschiedener Intentionen im ältesten und daher als für den besten erachteten Kodex A nachgewiesen. ${ }^{39}$ Seine Argumentation ist meistens sehr überzeugend. In seinen früheren Arbeiten versuchte er, im 10 839-zeiligen Euvre etwa 247 Verse als interpoliert zu charakterisieren. Hier kann meine Überzeugung, dass auch die letzte, zwar ,schwächere“, „konfusere“ Strophe zum originalen Gedicht gehört, weder von den Abweichungen der handschriftlichen Überlieferung (es gibt hier auch gar keine Abweichung in den Handschriften!) noch von der ästhetisierenden und nicht allzu starken Argumentation entkräftet werden. Mit den Gefahren einer zirkulären Argumentation rechnend denke ich, dass die offenkundigen thematischen Symmetrien die Verszahl von 208 (52 Strophen) verlangen. (Merkwürdigerweise hat sich Gnilka verrechnet, und die Zeilen 205-208 hält er für die Strophe 53. ${ }^{40}$ )

Das ursprüngliche Gedicht ordnet die Beschreibung des Weges der Weisen aus dem Morgenland von Persien bis nach Bethlehem mit hier nicht zu detaillierenden Symmetrien und inhaltlichen und numerischen Entsprechungen an, dann die Geschichte des bethlehemitischen Kindermords und die mit typologischem Symbolismus gesammelten Beispiele aus dem Alten Testament.

Die Struktur des ursprünglichen Prudentius-Hymnus wird durch die folgende Abbildung zusammengefasst:

\begin{tabular}{|c|c|c|c|c|c|c|c|c|}
\hline & & & & 52 & & & & \\
\hline 6 & 7 & 6 & 4 & 6 & 4 & 6 & 7 & 6 \\
\hline Stern & Aagier & Weg & Bethlehem & Herodes & Unschuldige & Moses & duces & Christus-König \\
\hline
\end{tabular}

${ }^{38}$ GNILKA, CHR.: Unechte Strophen im Prudentiustext. Prud. cath. 12. [205-208] und perist. 2. [17-20]. In Philologische Streifzüge (Anm. 2) 441-458; zum vorigen Hymnus s. 441-454.

${ }^{39}$ GNILKA, CHR.: Prudentiana I. Critica. München-Leipzig 2000. S. dazu A. CoşKUNs Rezension in Bryn Mawr Classical Review 2001. 11. 17.

${ }^{40}$ Z. B. $443-444$. 
Prudentius, Cathemerinon XII: HYMNUS EPIPHANIAE $\rightarrow$ „Prudentius“": DE INNOCENTIBUS

Audit tyrannus anxius adesse regum principem, qui nomen Israel regat teneatque David regiam.

Exclamat amens nuntio: „Successor instat, pellimur; satelles, $i$, ferrum rape, perfunde cunas sanguine!

Mas omnis infans occidat, scrutare nutricum sinus, interque materna ubera ensem cruentet pusio.

Suspecta per Bethlem mihi puerperarum est omnium fraus, ne qua furtim subtrahat prolem virilis indolis."

Transfigit ergo carnifex mucrone districto furens effusa nuper corpora animasque rimatur novas;

locum minutis artubus vix interemptor invenit, quo plaga descendat patens, iuguloque maior pugio est.

O barbarum spectaculum! Inlisa cervix cautibus spargit cerebrum lacteum, oculosque per vulnus vomit

aut in profundum palpitans mersatur infans gurgitem, cui subter artis faucibus singultat unda et halitus.

Salvete, flores martyrum, quos lucis ipso in limine Christi insecutor sustulit ceu turbo nascentes rosas!

Vos, prima Christi victima, grex inmolatorum tener, aram ante ipsam simplices palma et coronis luditis.

Quo proficit tantum nefas, quid crimen Herodem iuvat? Unus tot inter funera inpune Christus tollitur.

Inter coaevi sanguinis fluenta solus integer, ferrum, quod orbabat nurus, partus fefellit Virginis.

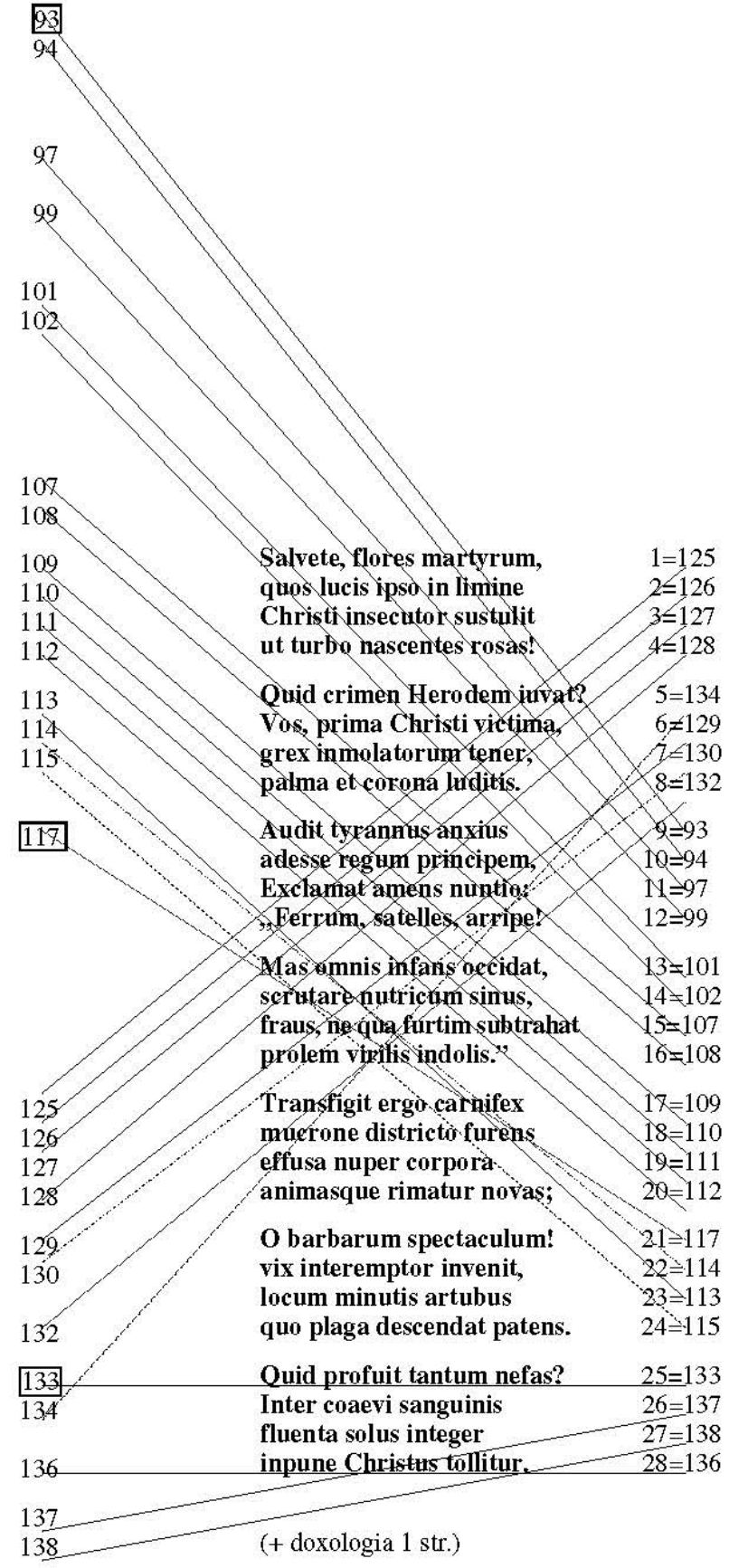


Prudentius, Cathemerinon XII: HYMNUS EPIPHANIAE $\rightarrow$ „Prudentius“: DE INNOCENTIBUS

Deutsch von Michael Chorlier

Voll Furcht vernahm es der Tyrann, dass der König der Könige gekommen sei, der das Geschlecht Israel regieren und das Königtum Davids besitzen soll

Außer sich von dieser Nachricht rief er aus: „Ein Nachfolger erhebt sich, uns zu vertreiben, Wachen, eilt und zückt das Schwert, und tränkt die Wiegen im Blut!

Tötet alles, was an Kindern männlich ist forscht, was die Ammen in ihrem Schob halten, und an der mütterlichen Brust

röte das Blut der Bübchen euer Schwert.

Verdächtig des Hochverrats erscheint mir zu Bethlehem jede Wöchnerin, und dass mir keine heimlich mit ihrem Jungen unbeschadet davonkommt."

Da durchbohrten die Schlächter tobend mit blanken Schwertern die gerade erst geborenen Leiber und schnitten das junge Leben ab;

an den kleinen Körpern den Ort kaum fanden die Mörder,

wo sie zusto ßen sollten,

da doch der Dolch gröber als die Kehle ist.

Was für ein barbarischer Anblick! Ein Schädel, zerschmettert an Felsen verspritzt das milchweiße Hirn, und speit die Augen aus wunden Höhlen.

Oder dort, ein zitterndes Kind geschleudert in einen tiefen Strudel, dem in der zarten Kehle Wasser und Atem sich röchelnd vermischen.

Seid gegrüßt ihr Märtyrerblïten, ihr, die euch an der Schwelle zum Leben der Verfolger Christi niederstreckte wie der Wirbelsturm die knospenden Rosen!

Ihr zarte Herde der ersten

die für Christus zu Opfern wurden -, vor seinem allerhöchsten Thron spielt ihr nun in kindlicher Einfalt mit Palme und Kronen.

Doch was erbrachte diese Untat? Was nützt Herodes dieses Verbrechen? Als einziger in all diesem Morden entkam doch Christus unverletzt.

In den Strömen von vergossenem Blut der Altersgenossen, entging allein, der Sohn der Jungfrau dem Eisen, das den Ehefrauen ihre Kinder entriss.

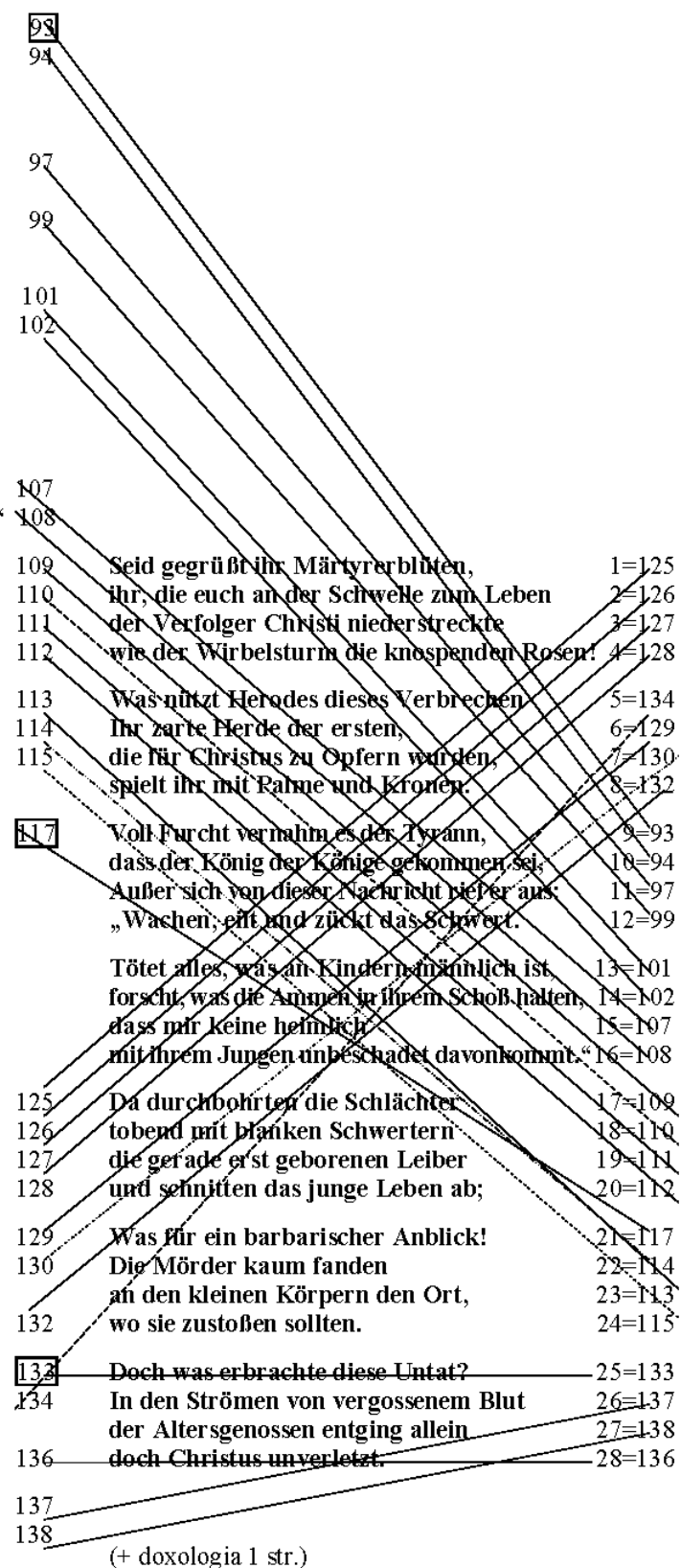

(+ doxologia 1 str.) 
Die inhaltliche Gliederung des Textes ist im Allgemeinen ziemlich eindeutig, die in verschiedenen Zeiten gemachten „Ausschnitte“ kreuzen unbewusst, ohne literarische Analyse, im Allgemeinen in diesen offenbaren Punkten die liturgischen Hymnen: Das frühneuzeitliche $O$ sola magnarum urbium entspricht dem Bethlehem-Teil, unser Hymnus Salvete flores martyrum beginnt den Ausschnitt des originalen Stoffes mit der Anfangszeile des Herodes-Teils (Audit tyrannus anxius). In der frühen Neuzeit ist dieser auch zum Hymnusanfang geworden. Der Teil, in dem das Martyrium der Unschuldigen Kinder beschrieben wird, separiert sich auch eindeutig. (Die von mir gemeinten Teilgrenzen bezeichne ich in der Abbildung mit der Platzierung der Ordnungszahl im Quadrat.)

\section{DIE „AMBROSIANISCHE“ ÄSTHETIK}

Um die Richtung der Umformung und deren vermutliche Prinzipien anzugeben, fasse ich noch einmal detailliert die inhaltlichen und strukturellen Charakteristika von Ambrosius' Hymnen zusammen. Vor allem teilt er die biblische Bestimmtheit und inhaltliche Ökonomie der Hauptlinie der westlichen christlichen Liturgie. Wie ich erwähnt habe, scheint die römische Liturgie (deren Varianten auch die benediktinisch-mönchische, dann die fränkisch-römische sind), im Gegensatz zu den östlichen orthodoxen und orientalischen Kirchen wie im Westen z. B. zu der ausschweifenden mozarabischen oder der weniger bekannten gallikanischen oder beneventanischen Liturgie, für eine Zeit lang jedem Eindringen der nichtbiblischen Dichtung in das prinzipiell aus dem Text der Bibel zusammengestellte Lesungs- und Gesangsmaterial starken Widerstand geleistet zu haben. Den Umbruch bedeuteten weder die dem Stil der Psalmen folgende liturgische Dichtung, die ausschweifender war als die heute bekannte (Te Deum, Exsultet, Gloria usw.), noch die langen Gedichte des Hilarius, die für epischdidaktisch zu halten sind, sondern Ambrosius' wenige, vermutlich zwölf Hymnen, die von elementarer Wirkung waren und die sowohl der Norm der biblischen Beschaffenheit des Materials entsprachen als auch den römischen Geschmack befriedigten.

Charakteristisch ist die Dialektik, dass Ambrosius' Hymnen einerseits mit ihren Umfangsgrenzen, mit der Organisation des achtstrophigen Rahmens ohne ,äußerliche" oder wenigstens zu auffällige Mittel (zum Beispiel Symmetrien, sich stark abgrenzende epische Einschübe; hier scheint er der Tradition römischer carmen-Dichtung zu folgen), mit der Anwendung der Wiederholung und der häufigen Parallelismen (parallelismus membrorum), mit biblischen Zitaten sehr wohl in die biblischen dichterischen Texte, das heißt in die durchschnittlich umfangreichen Psalmen, passten (oder in die in solche Passagen trennbaren, wie der Psalm 118/119). Das heißt, sie folgen einer Norm - andererseits wurden sie zu normativen und gattungsstiftenden Texten. Sie verfestigten und formten gleichzeitig die liturgische Ökonomie und den liturgischen Stil. Die Gedichte des Ambrosius wurden (einerseits durch die außergewöhnliche Autorität des mailändischen Bischofs, andererseits durch die Qualität des nicht umfangreichen, aber durchdachten und gattungsbegründenden Korpus) in der Tat zum Maßstab und Grund, sich auf sie zu berufen. 
Der Mit-Dichter des Salvete flores martyrum - erstmal benutze ich das Wort im Singular - scheint mir das fertig übernommene Prudentius-Gedicht nach dem Gedichttyp des Ambrosius zu richten, gleichzeitig hat er es jedoch nicht einfach als Rohstoff benutzt, sondern einige seiner Charakteristika wurden auch in der Struktur bewahrt. Fürs Erste hat er durch die Ausgestaltung der sieben Strophen, zu denen nach den Anforderungen der in die Offizienliturgie passenden Hymnen eine doxologische Schlussstrophe tritt, gerade eine achtstrophige Form zustande gebracht; dadurch entsprechen sie vollkommen den Ambrosius-Hymnen. (Die anderen, häufigeren liturgischen „Prudentius"-Hymnen sind kürzer, z. B. sind die Laudes-Hymnen mit der Doxologie fünfstrophig! Die achtstrophige Form wurde nämlich in der mittelalterlichen lateinischen Hymnendichtung nicht obligatorisch.) Der Mit-Dichter hat allerdings nicht davon abgelassen, die Symmetrie der Originale irgendwie wiederzugeben. Zwei Strophen bilden die Anrede der Unschuldigen Kinder, dann repräsentieren in einer veränderten Modalität drei Strophen die objektive Beschreibung des Kindermords, dann folgen zwei Strophen, die einerseits selbst Teil der Geschichtserzählung sind, aber durchwoben mit einem auf Reflexion hindeutenden Ausruf und mit einer Frage. Diese schöne Rahmenstruktur wird allerdings durch die doxologische Strophe umschrieben und so bewegt sich der Hymnus innerhalb der Ambrosius-Hymnodie.

Es liegt auf der Hand, aber man muss bemerken, dass das Salvete flores martyrum nach den antiken Gattungsanforderungen des Hymnus und nach der Gattungsnorm der Ambrosius-Hymnodie (die ein paar Jahre nach ihrer Entstehung bei Prudentius schon wirkt) mit einer Anrede anfängt; ${ }^{41}$ schon deshalb war es eine glückliche Entscheidung, das Gedicht mit der Zeile Salvete flores martyrum anzufangen. Indem wir nach den ersten zwei anredenden Zeilen ohne Übergang von dem Ort des im Himmel sich verklärenden Martyriums (palma et corona luditis) zum irdischen Schauplatz des Martyriums zurückkehren, eintauchen, kommt eine balladenhafte Montagetechnik zustande, die ausdrücklich für ein Charakteristikum der von den Heiligen handelnden AmbrosiusHymnen gehalten werden kann. So wird aus dem umfangreichen, aber wegen der Struktur nicht ausschweifenden Prudentius-Gedicht ein dichtes ,ambrosianisches“ Gedicht.

Der liturgische, ästhetische Grund der Auslassung der Zeilen/Strophen ist auch ziemlich offensichtlich. Der neoklassische Geschmack des letzten Jahrhunderts tadelte $^{42}$ im Gedicht des Prudentius die Beschreibung der schrecklichen Details, in der er an der Geschmacklosigkeit seiner Landsmänner teilzuhaben schien. (Mindestens dem hispanophoben französischen Lavarenne...) In der Tat ist, selbst wenn nicht das „Wort des Hispanier-Landes“, dann doch die literarische Wirkung von Prudentius' hispanischen Landsmännern, von Seneca und von Lukan anzunehmen. Für uns ist allerdings gerade seine grobe und brutale Darstellung der Realität eine seiner wichtigsten Tugenden. Es ist allerdings auch sicher, dass die allzu detaillierte Exponierung der Qual der Kindermärtyrer nicht vereinbar mit dem Kompaktheitsideal der Ambrosius-Gedichte ist. Genug ist das „konventionelle“, zwar nicht gewöhnliche, so

\footnotetext{
${ }^{41}$ Mohrmann, Chr.: La langue et le style de la poésie latin chrétienne. In MoHRmann, Chr.: Études sur le latin des chrétiens. Tome I. Edizioni di storia e letteratura. Roma 1961, 167 über die Veni Redemptor gentium. (Originalausgabe in Revue des Études latines XXV [1947].)

${ }^{42}$ Lavarenne, M. (ed.): Prudence. Tome I: Cathemerinon liber. Paris 1943, XIII.
} 
doch gewohnte Mordinstrument, die Benutzung des Schwertes - das am Fels herausspritzende Kindergehirn und die Beschreibung des im Wasser erstickenden Kindes übertreten schon die Grenze der liturgischen Duldsamkeit. Es ist dann keine Überraschung mehr, dass die Zeilen 118-124 des originalen Gedichts nicht ohne Empörung zu erregen in ein schon eindeutig für gemeinschaftliche Vorstellung bestimmtes Lied passen - und sie sind auch nicht im liturgischen Hymnus zu finden. Was also in einem nicht-liturgischen, sondern sicher höchstens dem Privatgebet zugehörigen Gedicht am Platze ist, der starke Effekt mit der ästhetischen Kraft des detaillierten Schreckens, das ist sowohl aus Gründen des Umfangs als auch aus thematischen Gründen eine unerträgliche Pervertiertheit in einem gemeinschaftlichen Lied.

Es ist mehr als Geschicktheit, aber als Geschicktheit ist es auch nicht zu verachten, wie sich die jeweils einzeiligen Syntagmen, ein Satz oder Sätze zu einer vernünftigen und neuen Ordnung zusammensetzen. Obwohl ich hier diese Behauptung nicht beweise, kann doch die Konsequenz aus aufmerksamem Studieren, meine ich, gezogen werden, dass es bei dieser virtuosen Cento-Technik weder um eine aus fehlender Inspiration stammende Halblösung noch um eine Notlösung geht, sondern um ein Werk eines Dichters, der die literarische techné meisterhaft beherrscht, das heißt, er ist selber mit Sicherheit ein Dichter.

Vor einigen Jahren verglich ich in folgender Weise Prudentius' für die Tageszeiten geschriebene und festliche Hymnen als Zyklus und Ambrosius' ebenso für die Tageszeiten (das heißt, nicht für die Heiligen) geschriebene Hymnen, des Weiteren die für die Heiligen geschriebenen Hymnen beider Autoren: ${ }^{43}$

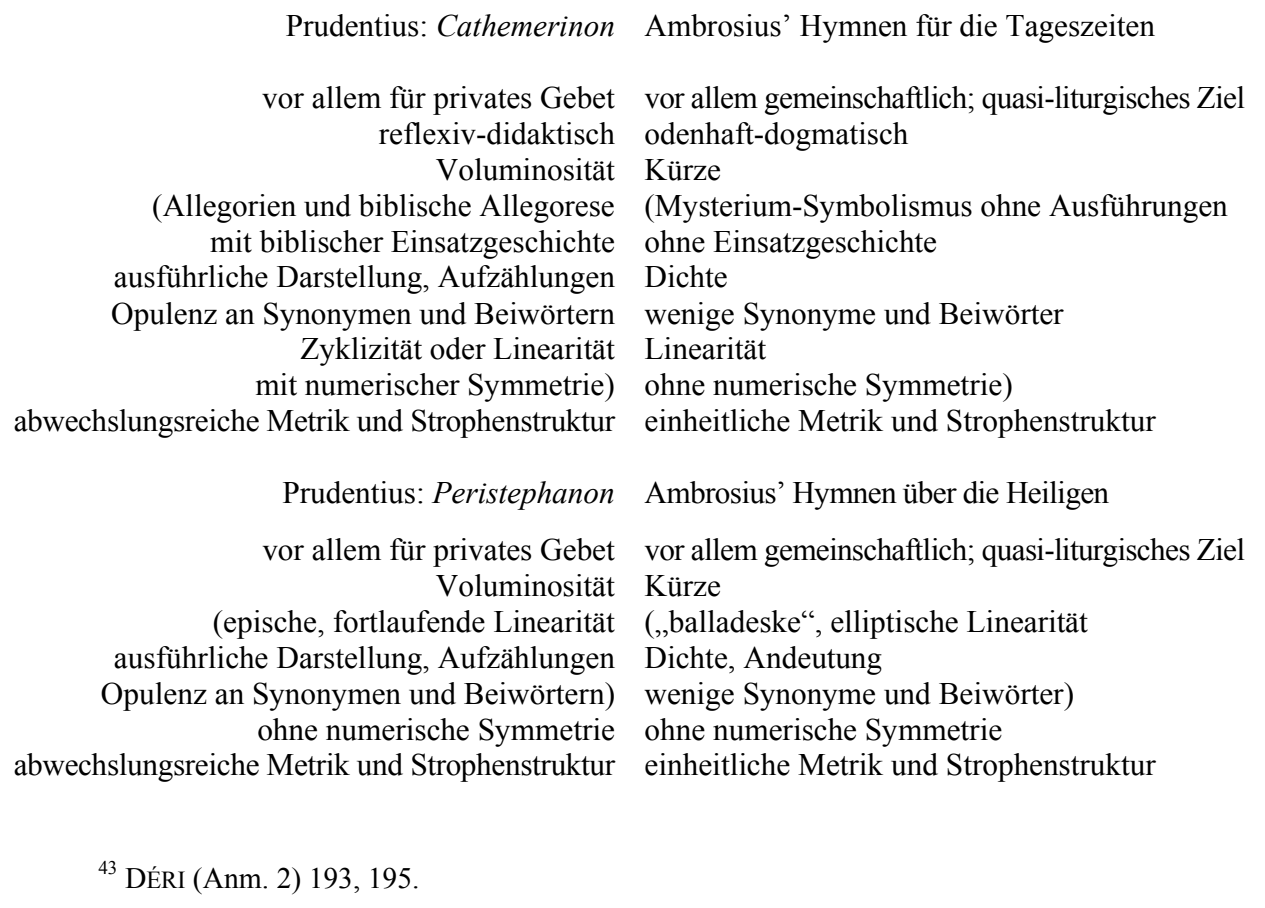


(Es sei bemerkt, dass zwar das Salvete flores für die Unschuldigen Kinder geschrieben wurde, aber ihre Geschichte bei Prudentius nicht unabhängig, sondern ein epischer Einsatz eines festlichen Gedichtes ist. Da diese Geschichte jetzt unabhängig wurde, ging sie in einiger Hinsicht in die Hymnen über die Heiligen über, so dass einige Züge von ihnen aus dem einen, andere aus dem anderen Vergleich zu gewinnen sind.)

Ich versuche kurz zusammenzufassen, inwiefern das originale Epiphanie-Gedicht des Prudentius in einen ambrosianischen Hymnus übergegangen ist.

Dass die Hymnen des Ambrosius mit einem gemeinschaftlichen, quasi-liturgischem Ziel verfasst wurden, wird durch die zeitgenössischen Berichte, vor allem durch die des Augustinus, aber auch durch die des Ambrosius bewiesen. Weder die mailändische „Vigilia“, für die er es nach der Anekdote des Augustinus geschrieben haben soll (Confessiones 9. 7. 15), noch die private Verwendung, die auch Augustinus bezeugt (ebda. 9. 12. 32), stellen die Gedichte des Ambrosius als eine feste liturgische Dichtung stabilen Status heraus - aber spätestens seit dem 6. Jahrhundert erwiesen sie sich als dazu geeignet. Man weiß wenig über die „Ziele“ des Prudentius. Nach den Ergebnissen der Forschung ${ }^{44}$ kann man sich zwar eine fromme, religiöse Gemeinschaft um sie herum vorstellen - diese Dichtung macht aber durchaus die private Verwendung als primären Seinsmodus wahrscheinlich. Diese Funktion müsste Beschaffenheit und Umfang der Gedichte bestimmt haben, aber auch ihre metrische Struktur.

Die für die Tageszeiten geschriebenen und die festlichen Gedichte des Prudentius charakterisiere ich als reflexiv-didaktisch, und das bringt automatisch die Voluminosität mit sich. Ersteres macht sowohl die ausführliche Darstellung des Gegenstandes der Reflexion erforderlich (wie einer wichtigen Naturerscheinung allgemeiner Bedeutung oder eines menschlichen Aktes eines biblischen Narrativs), als auch die ausführliche Reflexion, und indem es das Didaktische mit sich bringt, bedarf es logischerweise einer umfangreichen Ausführung. Die Forschung (man den$\mathrm{ke}$ in erster Linie an J.-L. Charlet ${ }^{45}$ ) hat im Cathemerinon des Prudentius sowohl die Rolle der langen biblischen Einsatzgeschichten als auch die verbreitete Verwendung der Allegorese und des typologischen Symbolismus (als Unterart dieser) ausführlich beschrieben. (Ein seltener, aber für Prudentius typischer Zug ist die dramatische Verwendung von Ausrufen, mit dem Ziel, die Narration zu beleben.) Mit den Beiwörtern „odenhaft“ und „dogmatisch“ deute ich einerseits auf die römische, horazische Odentradition, darauf, was man ungenau „Gedankenlyrik“ nennt, auf den Begriff, mit dem man zu beschreiben versucht, dass der Gegenstand der Reflexion und die Reflexion selbst überblendet werden - andererseits auf die potenzielle Energie der dichten Gedrängtheit der Dogmen hin. Die poetische Strukturierung des umfangreichen Gedichtes bringt zwangsläufig ,äußere“, aber in der griechisch-römi-

\footnotetext{
${ }^{44}$ LuDWIG, W.: Die christliche Dichtung des Prudentius und die Transformation der klassischen Gattungen. In Christianisme et formes litteraires de l'antiquité tardive en occident [Entretiens sur l'antiquité classique XXIII]. Genève 1977, 303-363.

${ }^{45}$ ChARLet, J.-L.: La création poétique dans le Cathemerinon de Prudence. Paris 1982.
} 
schen poetischen Tradition elaborierte Mittel mit sich, wie die Zyklizität und die numerischen Entsprechungen oder eben die numerisch beschreibbaren Symmetrien. Die abwechslungsreiche, für Connaisseure gedachte Metrik (in der man ebenso das Moment der Christianisierung der horazischen Strophen, man könnte sagen, den Gestus Dicar ... Horatianum carmen ad Christianos modos deduxisse, beobachten kann wie bei Horaz die Eroberung der äolischen Metrik) und ihr gegenüber die gemeinschaftliche/kollektive Einfachheit und Stabilität resultieren eben aus der Funktion.

Da der mittelalterliche Hymnus durch die Übernahme ganzer Zeilen entstand, blieb die Opulenz an Beiwörtern zwangsläufig präsent. Man kann höchstens feststellen, dass im Prudentius-Gedicht während der lebendigen Narration vielleicht weniger Beiwörter vorhanden sind, aber immer noch mehr als im Durchschnitt bei Ambrosius. Das mittelalterliche Gedicht hat auch das dramatische, direkte Zitat beibehalten (Satelles, i, ferrum rape... - ganz eigenartig im Korpus der mittelalterlichen Brevierhymnen, und wenn man es, wie erwähnt, ohne die doxologische achte Strophe betrachtet, kommt auch die für Prudentius so charakteristische Rahmenstruktur vor, hier: 2-3-2). Da jedoch, wie erwähnt, der Verfasser des Salvete flores martyrum aus Prudentius' Gedicht nur eine biblische Einsatzgeschichte und die Reflexion dieser hervorhebt, muss man den Text im Rahmen des anderen Vergleichspaares untersuchen. Schon die Abbildung zeigt, dass die Ausführung der Eigenschaften der ambrosianischen Heiligen fast ganz all das summiert, was ich während der Analyse des Salvete flores martyrum gezeigt habe. Der Aspekt der Kürze bringt die balladeske Narration und so das Dichten, das Andeuten mit sich.

Das mittelalterliche Gedicht hat grundsätzlich in seiner Stilistik die Treue zu Prudentius bewahrt, in anderer Hinsicht kam aber ein Ambrosius-Gedicht zustande, prinzipiell ohne Zufügung eines einzigen fremden Wortes.

Wer ist also der Autor des Gedichts? Prudentius? Nur deshalb, weil das Gedicht aus seinen Zeilen und Strophen zusammengefügt ist?

Aber wird z. B. Vergil als Autor der Centos der Proba angeführt? Auf keinen Fall. Als Antwort auf die Gegenargumente könnten wir die Frage stellen: Im Vergleich zu diesem antiken Beispiel ist es ein hinreichender Unterschied, dass wir einerseits den Namen des Cento-Machers (wie dort den der Proba) nicht kennen, andererseits dass diese Frau aus dem 4. Jahrhundert die jeweilige Zeile aus den verschiedenen Vergil-Werken in einem ganz anderen Rahmen platziert, während es in den behandelten Hymnen um die Umformung eines abgrenzbaren Teiles geht, und dass es hier statt des lächerlichen oder (wie Hieronymus meint ${ }^{46}$ ) enervierenden Textes der Proba um eine wirkliche ästhetische Qualität geht, das heißt, das originale Werk des großen Dichters durch den sekundären Text durchscheint? In gewissem Sinne ist dieser Hymnus in der Tat kein mittelalterliches Gedicht, und zwar nicht deshalb, weil wir ihn wegen unserer modernen Einstellung zu dem Autor und zu

\footnotetext{
${ }^{46}$ Hieronymus, Briefe 53. 7. (Ad Paulinum de studio Scripturarum): ... garrula anus ...; quasi non legerimus homerocentonas et virgiliocentonas ...
} 
seinen Rechten nicht dafür halten würden, sondern weil es in dem liturgischen Textzusammenhang - die kanonischen biblischen Texte ausgenommen ${ }^{47}$ (auch bei diesen nicht immer) - nicht nur keinen Platz für die Anführung des Autors gibt, sondern wir es so halten, als hätten sie keinen Autor. (Sie haben allerdings nach der Meinung des religiösen Menschen einen, der sie inspiriert, den Heiligen Geist.) Die nichtbiblischen, im Allgemeinen strophisch-metrischen literarischen Schöpfungen des Offiziums und der Messe, die in breitem literaturhistorischem Sinne Hymnen, ${ }^{48}$ als literarische und musikalische liturgische Gattungen Offizien- oder Prozessionshymnen, Sequenzen, Tropen genannt werden, waren an dem gegebenen liturgischen Ort und in der gegebenen liturgischen Gemeinschaft im Prinzip anonyme Gedichte, auch für jene mittelalterlichen Menschen (für nicht wenige), die sonst wussten, dass der Autor eines Hymnus, zum Beispiel eines Prudentius-Hymnus, sogar sehr bekannt war, da ein vollständiger Prudentius-Kodex - sagen wir - in der Bibliothek vorhanden war.

Dann wäre also der mittelalterliche Hymnus Salvete flores martyrum (zusammen mit ähnlichen Texten) kein Prudentius-Gedicht?

In einer Weise ist er es gewiss, besonders wenn man die schon erwähnte Centonisation für die im Frühmittelalter charakteristische, seriöse, nicht spielerische und nicht in ihrer Entwicklung zurückgebliebene, sondern für eine sehr empfindliche und fruchtbare literarische (und musikalische) Technik hält, ${ }^{49}$ die bedeutend für die Schaffung bestimmter liturgischer Textgattungen ist, sogar für ein so universales Verfahren, das die immer wiederkehrende Textgruppe der für die einzige Großform zu haltenden liturgischen Gelegenheit (einer Gebetstunde, einer Messe), eines liturgischen Tages, einer Woche, eines Zeitabschnitts und schließlich eines liturgischen Jahres fortwährend zustande bringt. (Leider haben wir hier keinen Raum, um zu zeigen, in welchen liturgischen Text- und Musikrahmen der Hymnus eingebettet ist. Diesen Rahmen sollten wir uns so vorstellen, als ob er das Libretto einer Oper in mehreren Akten bzw. ein Singspiel wäre, in dem sich das solistische prosaische Aufsagen des Textes, die lyrische Arie, das Duett und der Chor abwechseln.)

\footnotetext{
${ }^{47}$ Ich denke an die Einleitung der Vorlesung der biblischen Schriften, z. B. „Sequentia sancti Evangelii secundum Ioannem“.

${ }^{48}$ So allgemein verstehen viele den Terminus „Hymnus“. Ich, ausgenommen wenn ich über die Gedichte des Prudentius schreibe, für sie den antiken Begriff hymnus anwendend, verstehe darunter nach der Praxis der Musikwissenschaft, der liturgischen Literaturwissenschaft und der Kirchenmusik einen Offiziums- oder Prozessionshymnus. (Die Gedichte des Prudentius gehören in der liturgischen Anwendung in die erste Kategorie, bis auf den Hymnus Inventor rutili, der aus den ausgewählten Zeilen des fünften Gedichtes des Cathemerinon besteht und der in einem Teil Europas, so auch im mittelalterlichen Ungarn, das Lied der Zeremonie der Feuerweihe der Vigilia vom Karsamstag ist.)

${ }^{49}$ So ist beispielsweise der Graduale-Satz der lateinischen Messe, dessen zwei Teile aus ein bis zwei „Versen“ desselben oder verschiedender Psalmen zusammengebastelt sind und dessen künstlerische Wirkung aus der Zusammenstellung zweier, auf bestimmte Weise gegensätzlicher Teile stammt. (Teilweise ist dies auch bei der musikalischen Seite der Fall.)
} 


\section{DIE ART UND WEISE UND DIE ZEIT DER INTERPRETATIONSGEMEINSCHAFT}

Versuchen wir schließlich den Mitautor zu finden. Ich schicke vorweg, dass ich eine bestimmte Person nicht nennen kann, und das ist nach der jetzigen Lage unserer historischen und anderen Quellen auch unmöglich, umso mehr kann ich eine Interpretationsgemeinschaft vermuten, in der der oben genannte Schaffungsprozess vollzogen wird. Aus den Prudentius-Hymnen geformte kurze Laudes-Hymnen tauchen in den irländischen Hymnarien aus dem 8. bis 9. Jahrhundert, dann in den englischen Hymnarien aus dem 9. bis 10. Jahrhundert mit dem bekannten Text auf, sie lassen sich im 10. Jahrhundert auch in vielen italienischen und so auch in Kodizes von Monte Cassino finden. ${ }^{50}$ Meines Wissens zieht die Fachliteratur daraus sehr richtig nicht die voreilige Schlussfolgerung, dass sie die Schöpfung des irländischen Mönchsstands gewesen sein müssen. Der in das 9. bis 10. Jahrhundert datierte Codex Bernensis 455 ist die gemeinsame Quelle von neun selten vorkommenden Centos. Das geprüfte Salvete flores martyrum taucht im 10. Jahrhundert in einem Freisinger Ritual und einem von Monte Cassino bzw. im Hymnarium von Monte Cassino auf. Diese Entstehungen bedeuten aber nicht ein ante quem non. Wenn man irgendeine schwache Annahme riskieren darf, dann können wir den Anfang der Prudentius-Centonisation ins 8. Jahrhundert datieren und ihre Blüteperiode (das Spätmittelalter und die frühe Neuzeit ausgenommen) ins 10. bis 11. Jahrhundert.

Unser Ziel ist aber nicht die Datierung, nur die Formulierung der Annahme, dass wir die umformulierende Gemeinschaft der Prudentius-Hymnen auch im irisch-englischen, im süddeutschen Mönchsstand, in Monte Cassino und wahrscheinlich in anderen wichtigen kulturellen Zentren, aber auch im die Tradition des Hilarius und Prudentius vertretenden Aquitanien begreifen können. (Man sollte nicht vergessen, der Bischof von Poitiers ist, ähnlich wie Hilarius, der auch die prudentianische Struktur fortführende Venantius Fortunatus aus dem 6. Jahrhundert.) Diese Gemeinschaft verstand und verehrte die bedeutenden Zyklen der spätantiken christlichen Dichtung, sie war jedoch so mutig, dass sie sie den Modellen der Ambrosius-Hymnen folgend mit der Centonisationstechnik neu gestaltet hat; anders gesagt, sie hat sie in den gefestigten Rahmen der Liturgie hineingeschnitten. Damit die „neuen“ Hymnen so erfolgreich werden konnten, ist mit Sicherheit die Initiative, aber mindestens die erste Rezeption einer diese literarische Tätigkeit verehrenden, hochqualifizierten Gemeinschaft durch Literaten oder durch einen Literaten von hervorragendem Geschmack, aber auf jeden Fall durch einen souverän individuell schaffenden Autor vollzogen worden.

\section{ZUSAMMENFASSUNG}

Die Hymnen von Prudentius haben also seit 1600 Jahren zwei Leben: einerseits als die originalen, gewöhnlich langen, mehrstrophigen Werke, die in eigenständigen

${ }^{50}$ DREVES (Anm. 6) 23-25.

Acta Ant. Hung. 56, 2016 
Manuskripten, mindestens mit der Formel des Incipits und des Expliziten - wenn es in dem gegebenen Manuskript vorhanden ist $^{51}-$, mit der Benennung des Autors (Aurelius Prudentius), dann seit der Zeit des Buchdrucks in den Textausgaben existieren; andererseits als die aus ihnen gefertigten „Ausschnitte“, Centos, die in unzähligen Mengen der entsprechenden liturgischen Stelle zugeordnet, ohne die Benennung des Autors zu finden sind. ${ }^{52}$ Das oft immer noch für barbarisch gehaltene, tatsächlich aber eine riesige transformierende Arbeit vollbringende, formative Frühmittelalter, entweder die das große europäische Denken begründende kulturelle Erneuerung („,karolingische Renaissance“) oder aber die in das reife Mittelalter hinüberführende postkarolingische Zeit, ordnete die Erbschaft des antiken Christentums (und das, was diesem noch zugeordnet wurde) ungefähr bis zur Jahrtausendwende zu einer ausgeglichenen, geschlossenen, aber variablen Struktur. In diesen Prozess passen auch die Gedichte des Prudentius: Der originale Zyklus und der aus dem Gedichtzusammenhang herausgenommene literarische Stoff wurden in einem umfassenden Korpus der einzelnen gesungenen Sätze, einzelner Stunden und des Kreises des liturgischen Jahres neu strukturiert, dieses wurde zu der geistlichen Nahrung einer großen intellektuellen Menge geordnet, während eine Elite auch die originale Vollkommenheit der Gedichte des „hispanischen“ Dichters aufbewahrt hat.

Balázs Déri Univ.-Prof.

Seminar für Latinistik

Eötvös-Loránd-Universität (ELTE) Budapest

Ungarn

deri.balazs@btk.elte.hu

\footnotetext{
${ }^{51}$ Die etwa 300 mittelalterlichen Manuskripte, besonders ein großer Teil der wichtigsten, enthält die Hymnuszyklen.

${ }_{52}^{5}$ In Fortsetzung der Tradition der mittelalterlichen Manuskripte gibt es sogar in den neuzeitlichen liturgischen Ausgaben keine Autorbenennung, zum Beispiel sind die Hymnen von Ambrosius genauso anonym wie die Werke der wirklich anonymen Autoren.
} 
